There is also the question of how the sexual act is performed ; if it is proiracted there is presumably a greater chance of contagion. It is worth noting that it is difficult to infect a male by experimentally inoculating pus containing gonococci into the urethra, and one venereologist of repute believes that infection occurs owing to pus being sucked into the urethra as a result of a partial vacuum being set up there after ejaculation. The above remarks, of course, are made on the assumption that no precautions are taken before, during, or after the sexual act.

\section{Granuloma Annulare}

Q.-What is the modern treatment of granuloma annulare of the hand?

A.-Granuloma annulare is not a disease entity but a reaction, an allergic manifestation, and behaves accordingly. There is no specific treatment, but the condition may clear up after biopsy, a fractional dosage of $x$ rays, or various loca applications. Histologically granuloma annulare is identical with the nodules seen in rheumatoid arthritis, but is of no serious significance. The patient should be investigated to exclude underlying disease, especially a tuberculous infection, which may have provoked the reaction, but a cause will rarely be discovered.

\section{Rectal Bleeding in an Infant}

0.-A breast-fed baby of 5 weeks is occasionally passing a little red blood per rectum; his haemoglobin is $85 \%$ (Sahli). How can iron be best conveyed to him? What investigations are needed and what is the treatment?

A.-A haemoglobin level is best expressed in grammes per $100 \mathrm{ml}$., as standards of the Sahli method (as of others) vary. Assuming that this is based on $100 \%$ Sahli being equivalent to $14 \mathrm{~g}$. of haemoglobin, then $85 \%$ for a 5 -weeks-old baby can be regarded as a normal level and not as evidence of anaemia. The need for giving iron therefore does not directly arise, as in fact it very rarely does for a breast-fed baby in the early weeks of life. The rectal bleeding should certainly be investigated: it may be due to a small fissure or a rectal polyp-to name likely conditions-which requires treatment.

\section{Typhoid and Pregnancy}

Q.-Is there any evidence that typhoid has any effect on the germ-plasm? A man and his wife have both had typhoid, and since then two pregnancies have resulted respectively in an early abortion and a monstrosity.

A.- None. The abortion and the monstrosity have no connexion with the previous typhoid fever in the parents. An attack of typhoid fever in a pregnant woman does frequently cause abortion, but this is a direct effect of the disease on the foetus.

\section{Derris Poisoning}

Q. -What are the signs, symptoms, and treatment of derrisroot poisoning? A man employed by a veterinary firm handled a consignment of derris root three weeks ago; he collapsed with intense vomiting, as did three others similarly engaged. $\mathrm{He}$ complains of malaise and abdominal discomfort, which he dates from the time of his coming into contact with the derris root; examination reveals nothing definite.

A. - There is evidence that fish are destroyed within 90 to 240 minutes in a $0.001 \%$ aqueous extract of derris. For this reason it is widely used as a fish poison by natives throughout the Tropics. The most common use of derris root, of course, is as an insecticide. A number of chemical compounds, some of them active as insecticides, have been isolated from the fishpoison plants. Of these compounds rotenone seems to be the most important in the case of derris. Animal experiments indicate liver damage on a diet containing derris. In man, however, apart from the irritating effect on mucous membranes and skin, there seems little evidence of the toxicity of this substance. Derris root has been used as an agent for suicide among the natives of New Ireland. In such cases vomiting has occurred before death, and the post-mortem changes were those of acute congestive heart failure. In industry, objectionable effects from derris dust can be overcome by adequate ventilation in grinding departments, and by use of suitable masks during both grinding and the application of sprays and dusts.
Treatment would be symptomatic, but it is important that further exposure should be controlled by the measures suggested above.

\section{"Benadryl" and Barbiturates}

Q.-A report is current in Iraq that an antagonism exists between "benadryl" and the barbiturates. If you can confirm this, would you give some indication of the reaction between the two chemicals?

A.-The only antagonistic reaction between "benadryl" and barbiturates referred to in the literature is that when benadryl is injected intravenously in animals in toxic doses it causes excitement and convulsions; these central effects are prevented by giving a barbiturate 30 to 90 minutes beforehand (Gruhzit and Fisken, J. Pharmacol., 1947, 89, 227). It is unlikely that this observation has any application to man, since toxic doses of benadryl are not commonly given. In some subjects benadryl causes mental confusion, hut there is no evidence that barbiturates affect this. It might be expected, however; that if a barbiturate had been given before the benadryl any confusion produced by the latter would be increased.

\section{Vitamin $K$ and Chilblains}

Q.- Are there any contraindications to the use of vitamin $K$ (recommended as a treatment for chilblains) in patients over 60 or who suffer from arteriosclerosis?

A.- There are no contraindications to the use of vitamin $K$ in patients over 60 , or at any age for that matter, or in patients who suffer from arteriosclerosis. It is a perfectly safe substance. There is insufficient evidence, however, to recommend it for use in the treatment of chilblains.

\section{NOTES AND COMMENTS}

Rh Factor and Pregnancy.-Dr. R. N. C. McCurdy (Ashtead) writes: It is of course impossible to give a complete answer on $\mathbf{R h}$ questions in a small space, but I think that incomplete answers may be misleading. For example, in "Any Questions?" (Jan. 1, p. 42) it is stated that "antibodies are unlikely to be present at five or six months in a first pregnancy, and there is little or no danger to the first foetus from this cause. ..." It is not pointed out in the answer, nor in Dr. S. A. Doxiadis's note (Jan. 22, p. 164), that there may be considerable danger to a first foetus if such a woman has ever received an injection of $\mathrm{Rh}$-positive blood, however small (Mollison et al., "Rhesus Blood Groups," 1948, M.R.C. Memo No. 19, p. 27), or has previously had an abortion. Under the heading "Repeated Stillbirths " (Jan. 29, p. 206) it is not pointed out that approximately $2 \%$ of women developing iso-agglutinins to $\mathbf{R h}$ are themselves $\mathbf{R h}$ positive and become sensitized to the agglutinogens $\mathrm{E}$ or $\mathrm{c}$ (Mollison et al., op. cit., p. 19).

Epsom College Centenary Register.-Dr. T. R. Thomson (Cricklade, Wilts) writes: I have undertaken the general editorship of the Register and I am finding great difficulty in tracing the parentage of many of the boys entering the College between 1855 and 1874 . I ask readers who have knowledge of these early entrants to write to me. The smallest clue may be useful.

Cholesteatoma.-Dr. MARK Hughes (Accra, Gold Coast, West Africa) writes: In "Any Questions ?" (Jan. 1, p. 41) an inquirer asks, "What are the pathology and treatment of a choles'eatoma?" The answer describes the rare meningeal tumour of that name and quite unaccountably fails to mention the exceedingly common condition of cholesteatoma of the middle ear.

Correction.-In our account of the debate on the Supplementary Estimates for the National Health Service (Feb. 26, p. 372) there was an error. "The cost of the actual individual prescriptions had been greatly increased . ..." should have read " had not been greatly increased.'

All communications with regard to editorial business should be addressed to $T_{H}$ EDITOR, BRITISH MEDICAL JOURNAL. B.M.A. HOUSE. TAVISTOCK SQUARE, LONDON, W.C.1. TELEPHONE: EUSTON 2111. TELEGRAMS: Aitiology, publication are understood to be offered to the British Medical Journal alone publication are understood to

unless the contrary b- stated. uthors desiring REPRINTS should communicate with the Publishing Manager, B.M.A. House, Tavistock Square, W.C.1, on receipt of proofs. Authors overseas shcu indicate on MSS. if reprints are required, as proofs are no sent abroad.

ADVERTISEMENTS should be addressed to the Advertisement Manager B.M.A. House. Tavistock Square, London, W.C.1 (hours 9 a.m. to 5 p.m.) TELEPHONE : EUSTON 2111. TELEGRAMS : Britmedads. Westcent, London MEMBERS SUBSCRIPTIONS should be sent to the SECRETARY of the Ass-ciation. TELEPHONE : EUSTON 2111. Telegrams : Medisecra, Westcent

B.M.A. SCOTTISH OFFICE : 7, Drumsheugh Gardens, Edinburgh. 